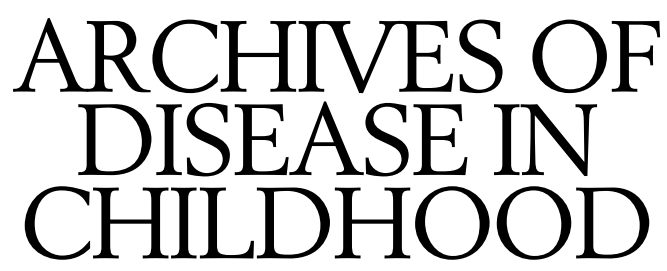

The Fournal of the Royal College of Paediatrics and Child Health

\title{
Annotations
}

\section{Rationing in child health services: a personal view}

Rationing in the UK National Health Service comes in many forms: there is choosing not to see something as a relative health problem in the first place; there are simple straight decisions not to fund treatments, investigations, preventive measures, etc because of lack of resources at that particular time; there is rationing by reasonable methods of priority setting at national and district level. There are also more insidious methods of delaying the implementation of treatments of proved efficacy that, on balance of evidence, should be used. Such delays are done by reassessing, demanding more information, claiming that it is someone else's responsibility, etc. There is also rationing by waiting lists and rationing by illogical resource allocation on the grounds of political expediency.

As a commissioner, while I am aware of these facts I am also aware that the NHS, compared with other health delivery systems used around the world, supplies an excellent "value for money" service that is "free at the time of delivery". It is just that we still, within the NHS and outside (particularly in political spheres) hate owning up to the fact in public that rationing has always been and will always be a necessity.

\section{Where has there been rationing in child health services?}

This will vary from one district to another. A quick look over the past four or five years of my own work in commissioning would include: rationing of all the treatment services for handicapped children; rationing the availability of medical services to severely disabled children placed "out of county"; lack of funding for triple testing pregnant mothers for Down's syndrome, which most studies show would significantly decrease the number of children being born with this condition; inadequate number of school nurses for ensuring correct giving of medications in schools and for supporting the needs of special needs children in schools; lack of funding for the introduction of a neonatal hearing screening programme; inadequate resources to support a community screening programme for growth problems in children; rationing of resources to adequately meet the mental health needs of children and young people; inadequate resources for funding community children's nursing; inadequate funding to develop an appropriate children's accident and emergency department area; rationing of money needed to rebuild proper paediatric inpatient facilities at a local district general hospital.
All these decisions were made with hugely varying degrees of consciousness, logic, and determination on the part of all those involved.

Is rationing worse within some areas of services for children than others?

Although, as suggested above, many different areas of paediatric and child health services have not been developed at a rate commenserate with need, there are some areas of delivery of child health services where rationing appears worse than others. Generally, neonatology and paediatric intensive care have a high political sensitivity for losing votes if something goes wrong, and tend therefore to achieve priority funding. From personal experience, it seems that money is far more easily obtained when it is being requested for acute hospital paediatric services than when the funds are being asked to support the long term care of severely handicapped children at home or in respite care. It may cost around $£ 20000$ on a one off basis to keep a very prematurely baby alive in a special care baby unit, but it will cost $£ 160000$ each year to meet a severely handicapped child's needs 52 weeks a year in respite care. Again these priority differences in the funding of children's services may vary greatly around the country, but I would doubt whether there is a single health district in England where commissioners can truly say there is not some area of rationing of their health services for children.

\section{Are there areas of services to children that I would} like to see rationed at the expense of others, given the overall limit on resources?

Yes, I believe that as a just and humane society we should not provide further funding for neonatal and other intensive care for children unless we can absolutely guarantee funding for fully supporting the long term needs of severely handicapped children and their families. Personally, until that happens, there are children and families where it would be far more humane to allow a very severely handicapped child to die of natural causes, rather than to keep that child alive at any cost. Further, I think that we need to re-examine the overall funding mix between "new treatment hi-tech" to meet the needs of a few children and the straightforward health care of all children. Perhaps, just perhaps, the national institute of clinical excellence (NICE) may move us towards this goal. 
Can we make more logical choices about rationing than we do at the moment?

Yes, in many different ways, but by far the most important is by making priority setting at national and local level more logical, more transparent, with greater public involvement, and based on good information rather than on emotive issues. Too many of the national decisions about rationing and priority setting are still made on the grounds of being "vote getting" rather than based on need or relative effectiveness. Although this is inevitable it needs to be clearly stated and understood.

At a local district level, primary care groups, primary care trusts, and health authorities will, one way or another, increasingly need to involve the public in their decision making on rationing and priority setting. This will have to occur, whether the services concerned are for health services to children, or for other age and patient groups. One way of doing this has been developed by the Oxfordshire Health Authority who have set up and manage a "priorities forum". Representation on this forum is broad, multidisciplinary and includes academics in the field of medicine and ethics, acute hospital medical staff, community and primary care medical staff, public health personnel, and community health council members. The ethical framework of the forum is based around three key issues: effectiveness, equity, and patient choice. To achieve this the health authority provides "envelopes" of money for each clinical area and leaves most of the rationing and priority setting decisions about distribution of these funds to the medical staff within the individual clinical area. However, where the medical staff wish to develop a new service that requires considerably more funding, the priorities forum's first response is to question the doctors concerned as to why the new treatment cannot be funded from within this fixed envelope, and why, if the new treatment is more effective than the old, it cannot be funded by dropping other less effective treatments within the same area of work.
If this cannot be achieved then consideration is given by the priorities forum as to whether the development is so important that resources should be moved between envelopes to achieve the needed funding given that overall the health authority is working within absolute limits in the overall funding allocated to it by government.

\section{What are the consequences of such rationing and priority setting for paediatricians and others involved in child health care?}

Decision making about rationing and priorities need a holistic approach, which takes into account all the health related needs of children and which includes the child's social and educational needs as well as their direct health needs; therefore, decisions should be made in conjunction with colleagues from these disciplines. Within medicine itself the ever increasing number of new technologies being developed in the area of paediatrics means there is a concomitant inevitability that rationing of treatments will increase and that it will have to be done in an increasingly open and logical way. There are therefore two choices for those involved in the health care of children and young people when it comes to the question of rationing and priority setting. They can either stand aside and say "this is not our business, let someone else decide", which appears at the moment to be the majority decision (though the tendency remains to complain endlessly when the decision is made by others), or they can take part in these decisions, and have a voice in the choice, which increases the chances of the inevitable final decisions being more logical and in the best interest of children. The choice is ours.

Consultant in Public Health and Health Policy,

AIDAN MACFARLANE

Oxfordshire Health Authority,

Old Road, Headington,

Oxford OX3 $7 L G$, UK

\section{Pseudomonas and all that}

A French military surgeon in 1850 was the first to describe an infection with Pseudomonas aeruginosa when he discovered blue pus in the dressings of wounded soldiers. ${ }^{1}$ The colour resulted from the secretion by the bacterium of its characteristic pigment pyocyanin. By 1984 more than 102 different species were included in the family Pseudomonadaceae, most of which were plant pathogens or soil saprophytes. All are straight or curved Gram negative rods that are motile by polar flagella. Most are strictly aerobic, can grow in temperatures from $4-43^{\circ} \mathrm{C}$ and are usually oxidase positive. Application of DNA technologies to microbial taxonomy has led to further divisions within the Pseudomonadaceae. This has resulted in a proliferation of "new" genera and species much to the consternation of clinicians and clinical microbiologists alike.

The taxonomic tool used most frequently is analysis of $16 \mathrm{~S}$ and $23 \mathrm{~S}$ ribosomal RNA (rRNA) cistrons. These regions are relatively well conserved. For example, it is estimated that the average substitution (mutation) rate for $16 \mathrm{~S}$ rRNA within a particular eubacterium is $1 \%$ per 50 million years. ${ }^{2}$ However, there is sufficient variability to permit delineation of genera and species. This analysis can be done by DNA/DNA hybridisation but is currently most often achieved by polymerase chain reaction (PCR) amplification of a large portion of the $16 \mathrm{~S}$ rRNA gene and sequencing the amplicon; Pseudomonadaceae have thus been split into five rRNA groups (table 1).

\section{rRNA group I}

The most important human pathogen in this group is $P$ aeruginosa. It has a ubiquitous distribution in the environment and can adapt to living and multiplying in such unpromising habitats as distilled water and disinfectants. Sinks, taps, and drains in hospitals are always colonised but these isolates seem rarely to infect patients. It is not normally part of the skin, pharyngeal or intestinal flora. It will however colonise waterlogged skin, and can produce folliculitis and otitis externa. It is also a common cause of infections in burns, which can lead to septicaemia and death. $P$ aeruginosa can produce keratitis, corneal ulceration, which may progress to endophthalmitis, and orbital cellulitis. The most common sources for such infections are contact lens fluids and ocular medication. ${ }^{3}$

$P$ aeruginosa is an important cause of meningitis in neonates and of septicaemia in neonates and immune compromised children. ${ }^{45}$ It is also a cause of urinary tract infection in children with anatomic or functional abnormalities of the bladder. But it is in children with cystic fibrosis (CF) that $P$ aeruginosa is most frequently encountered. ${ }^{6} \mathrm{Up}$ to $90 \%$ of patients in $\mathrm{CF}$ clinics are 
colonised or infected with $P$ aeruginosa. Colonisation rates increase with age and are associated with an increased decline in lung function. ${ }^{6}$ Application of methods of genomic analysis such as pulsed field gel electrophoresis (PFGE) of macrorestricted chromosomal DNA, flagellin gene polymorphisms, or arbitrarily primed PCR (APPCR) have shown that epidemic strains of $P$ aeruginos a can spread among patients attending the same CF clinic. ${ }^{78}$

$P$ aeruginosa can produce a vast array of virulence determinants including adherence factors (pili), flagella (for motility), extracellular polysaccharides (alginate in mucoid isolates), proteases, (such as elastase), cytotoxins (leucocidin), and exotoxins. The exotoxins include exotoxin A, (which is closely related to diphtheria toxin and inhibits protein synthesis by ADP ribosylation of elongation factor 2 ) and exoenzyme $S$ (another ADP ribosyl transferase). Interestingly $P$ aeruginosa from patients with $\mathrm{CF}$ appear to be more often mucoid and non-motile, to have short polysaccharide side chains on their lipopolysaccharide (which render them serum sensitive), and produce fewer secreted proteins.

Our understanding of host-microbe interactions has been revolutionised in the past decade. It is clear that there is extensive biochemical "crosstalk" between bacteria and host cells. Thus the bacteria are influenced by their environment and in turn alter host cell behaviour. This is often mediated by type III secretion systems in Gram negative bacteria. ${ }^{9} 10$ Such systems are assembled in response to-for example, contact with host cells, and allow ATP powered secretion of unmodified proteins across the bacteria's two lipid membranes and their injection into host cells. The injected proteins often resemble eukaryotic signal transduction factors capable of stimulating or suppressing host cell intracellular messages. The genes for type III secretion systems are clustered together on the bacterial chromosome (with or without the secreted protein genes) and appear to be well conserved between a range of plant and animal pathogens. They have a different $\mathrm{G}+\mathrm{C} \%$ molar ratio from the rest of the bacterial chromosome and appear to have been acquired laterally during the evolution of pathogenicity. ${ }^{910}$ They have been termed pathogenicity islands ${ }^{10}$ and have been found in human pathogens such as Escherichia coli, Salmonellae, Shigellae, Chlamydia trachomatis, Bordetella pertussis, and Yersinia enterocolitica. Recently a type III secretion system has been found in $P$ aeruginosa, which secretes exoenzyme $S$ and other proteins related to Yersinia spp Yop B and D. ${ }^{11}$ Interestingly, mutant $P$ aeruginosa that were able to invade epi- thelial cells, were shown to have defects in this type III secretion system, were no longer cytotoxic, and did not secrete the Yop B and D homologues. ${ }^{12}$

\section{rRNA group II}

Burkholderia cepacia is an increasingly important opportunist pathogen, especially in $\mathrm{CF}$ and chronic granulomatous disease. ${ }^{13}$ In CF, acquisition of $B$ cepacia can be associated with rapidly declining lung function and death: the cepacia syndrome. ${ }^{6}{ }^{14}$ Although $B$ cepacia is highly prevalent in the environment, some strains have an enhanced capacity to spread from patient to patient and cause disease. ${ }^{6}{ }^{13} \mathrm{~A}$ highly transmissible strain of $B$ cepacia is ET12 (Edinburgh-Toronto electrophoretic type 12), which has spread to over half the CF clinics in the UK. ${ }^{15}$ ET12 expresses long intertwined cable pili and it, and other highly transmissible strains, all contain a novel DNA sequence $(1.4 \mathrm{~kb})$ "BCEM" (B cepacia epidemic strain marker), which is related to transcriptional regulators in other bacteria. ${ }^{16}$ A number of techniques are available to type $B$ cepacia isolates including PFGE, ribotyping, AP-PCR, and flagellin gene polymorphisms. ${ }^{6}{ }^{14} 16^{17}$ It is now clear that all $B$ cepacia strains are not the same and that colonisation with a low virulence strain does not prevent subsequent colonisation, infection, and death from more virulent ET 12. ${ }^{14}$ This of course poses further problems for control policies aimed at preventing acquisition of $B$ cepacia by patients with $\mathrm{CF} .{ }^{18}$

Virulence factors of $B$ cepacia are not completely defined but include attachment factors,${ }^{15}$ flagella, ${ }^{17}$ and extracellular enzymes. ${ }^{6}$ In mucous membranes where there is heavy bacterial colonisation, the mucin polysaccharide is sulphated, which is the case in the mucin from patients with CF. ${ }^{19}$ It is thought that sulphation protects mucin from degradation by bacterial glycosides. ${ }^{20}$ We have recently shown that some strains of $B$ cepacia and, to a lesser extent, $P$ aeruginosa have mucin sulphatase activity. ${ }^{21}$ Such activity might not only aid degradation of mucin but also expose new receptors for the bacteria.

$B$ malle $i$ and $B$ pseudomallei cause glanders and meliodosis, respectively. $B$ malle $i$ is primarily an equine pathogen and a rare zoonotic pathogen. $B$ pseudomallei causes meliodosis, an acute and chronic infection of man and other animals, and is endemic in South East Asia, Northern Australia and Papua New Guinea. However, it is present in soil in many other parts of the world, and infection is thought to be acquired through soil contamination of skin wounds, by ingestion or inhalation. It causes septi-

Table 1 Medically important pseudomonads

\begin{tabular}{|c|c|c|}
\hline$r R N A$ homology group & Species & Disease associations \\
\hline \multirow[t]{9}{*}{ (I) Pseudomonas } & $P$ aeruginosa & Eye, skin, wound and burn infections \\
\hline & & Septicaemia and meningitis in immune compromised patients \\
\hline & & Urinary tract infection with bladder defects \\
\hline & & Respiratory tract infection in CF \\
\hline & P fluorescens & Rare opportunist pathogens \\
\hline & P putida & Rare opportunist pathogens \\
\hline & Pstutzeri & Rare opportunist pathogens \\
\hline & $P$ alcaligenes & Rare opportunist pathogens \\
\hline & P pseudoalcaligenes & Rare opportunist pathogens \\
\hline \multirow[t]{7}{*}{ (IIa) Burkholderia } & B cepacia & Respiratory tract infection in $\mathrm{CF}$, opportunist \\
\hline & $B$ gladioli & Respiratory tract infection in $\mathrm{CF}$, opportunist \\
\hline & B multivorans & Respiratory tract infection in CF, opportunist \\
\hline & B pseudamalle $i$ & Melioidosis \\
\hline & $B$ mallei & Glanders in horses and man \\
\hline & $B$ thailandensis & Saprophyte, ?opportunist \\
\hline & $B$ vietnamensis & Saprophyte, ?opportunist \\
\hline (IIb) Ralstonia & R pickettii & Rare opportunist \\
\hline (IIc) Oxalobacter & O formigenes & Absence in normal flora of children with CF predisposes to nephrolithiasis \\
\hline \multirow[t]{2}{*}{ (III) Comamonas } & C acidovorans & Rare opportunist pathogens \\
\hline & $C$ testosteroni & Rare opportunist pathogens \\
\hline \multirow{2}{*}{ (IV) Brevundimonas } & $B$ diminuta & Rare opportunist pathogens \\
\hline & $B$ vesicularis & Rare opportunist pathogens \\
\hline (V) Stenotrophomonas & $S$ maltophilia & Respiratory tract infection in $\mathrm{CF}$, opportunist \\
\hline
\end{tabular}


caemia, pneumonia, osteomyelitis, and soft tissue (including brain) abscesses. It appears the bacterium can remain dormant, presumably in macrophages, to re-emerge years later. It is sometimes referred to as the "Vietnamese time bomb" as it is currently producing infection in US veterans of the Vietnamese war. It can be very difficult to treat and results in high mortality. We know little about its pathogenesis; however, a complex of genes encoding a type III section system has been found recently on the replicons of $B$ pseudomallei. ${ }^{22}$ In addition, exotoxins including cytotoxic glycolipids have been implicated in melioidosis. ${ }^{23} 24$

Oxalobacter formigenes is part of the normal enteric flora and breaks down oxalate to $\mathrm{CO}_{2}$ and formate. In children with $\mathrm{CF}$, carriage of $O$ formigenes is rare (only $16 \%$ of subjects), and over half of those not colonised are hyperoxaluric. ${ }^{25}$ It is conceivable that this is related to the increased risk of calcium oxalate urolithiasis in patients with CF.

\section{Other rRNA groups}

Each of the remaining bacteria is an opportunist pathogen. Stenotrophomonas maltophilia has changed names twice, from Pseudomonas to Xanthomonas then to its final designation. On nutrient agar it produces yellow colonies, (hence the previous Xanthomonas). It is widely distributed in the animate and inanimate environments, and can cause life threatening bacteraemia, endocarditis, and pneumonia. It is associated with respiratory tract infection in patients with $\mathrm{CF}$, generally late in the disease process. It is usually resistant to imipenem by expression of a carbapenemase, but most isolates are sensitive to ceftazidime, cefotaxime, cotrimoxazole or ticarcillin/clavulanate. There are many clinically useful combinations of cotrimoxazole and other agents in treating $S$ maltophilia infection. ${ }^{26}$

Although this represents the current taxonomic status of the Pseudomonadaceae, there will undoubtedly be further changes. For example, there are currently further divisions of $B$ cepacia into genomovars ${ }^{27}$ and movement of some isolates to different species. ${ }^{28}$

C A HART C WINSTANLEY

Department of Medical Microbiology and Genitourinary Medicine, University of Liverpool,

PO Box 147, Liverpool L69 3GA, UK

email:cahmm@liv.ac.uk

1 Pitt TL, Barth AL. Pseudomonas aeruginosa and other medically important pseudomonads. In: Emmerson AM, Hawkey PM, Gillespie SH, eds. Principles and practice of clinical bacteriology. London: John Wiley \& Sons, 1997:493-517.

2 Ochman H, Wilson AC. Evolution in bacteria: evidence for a universal substitution rate in cellular genomes. $7 \mathrm{Mol}$ Evol 1987;26:74-86.
3 Zloty P, Belin MW. Ocular infections caused by Pseudomonas aeruginosa. In: Baltoh AL Smith RP, eds. Pseudomonas aeruginosa infections and In: Baltoh AL, Smith RP, eds. Pseudomonas aerug

4 Thompson PJ, Greenough A, Hind MF, Philpott-Howard J, Gamsu HR. Nosocomial bacterial infections in very low birth weight infants. Eur $\mathcal{F}$ Pediatr 1992;151:451-4.

5 Dison P, Mackie E, Murphy N, Hart CA. Bacteremia in children: an eight year retrospective review. Pediatric Rev Commun 1992;6:211-20.

6 Govan JRW, Deretic V. Microbial pathogenesis in cystic fibrosis: mucoid Pseudomonas aeruginosa and Burkholderia cepacia. Microbiol Rev 1996;60:539-74.

7 Cheng K, Smyth RL, Govan JRW, et al. Spread of a $\beta$-lactam resistant Pseudomonas aeruginosa in a cystic fibrosis clinic. Lancet 1996;348:639-42.

8 Adams C, Morris-Quinn M, McConnel F, et al. Epidemiology and clinical impact of Pseudomonas aeruginosa infection in cystic fibrosis using impact of Pseudomonas aeruginosa infection

9 Hueck CI. Type III protein secretion systems in bacterial pathogens of animals and plants. Microbiol Mol Biol Rev 1998;62:379-433.

10 Mecsas J, Strauss EJ. Molecular mechanisms of bacterial virulence: type III secretion and pathogenicity islands. Emerg Infect Dis 1996;2:271-88.

11 Yahr TL, Mende-Mueller LM, Friese MB, Frank DW. Identification of type III secreted products of the Pseudomonas aeruginosa exoenzyme $S$ regulon. F Bacteriol 1997;179:7165-8.

12 Hauser AR, Fleiszig S, Kang PJ, Mostov K, Engel JN. Defects in type III secretion correlate with internalization of Pseudomonas aeruginosa by epithelial cells. Infect Immun 1998;66:1413-20.

13 O'Neill KM, Herman JH, Modlin JF, Moxon ER, Winkelstein JA. Pseudomonas cepacia an emerging pathogen in chronic granulomatous disease. F Pediatr 1986;108:940-2.

14 Ledson MJ, Gallagher MJ, Corkill JE, Hart CA, Walsh MJ. Cross-infection between cystic fibrosis patients colonized with Burkholderia cepacia. Tho$\operatorname{rax} 1998 ; 53: 432-6$.

15 Sun L, Jang R-Z, Steinbach S, et al. The emergence of a highly transmissible lineage of $\mathrm{cb} 1 \mathrm{~A}+$ Pseudomonas (Burkholderia) cepacia causing epidemics in North America and Britain. Nat Med 1995;1:661-6.

16 Mahenthiralingam E, Simpson DA, Speert DP. Identification and characterization of a novel DNA marker associated with epidemic Burkholderia cepacia strains recovered from patients with cystic fibrosis. F Clin Micrbiol 1997;35:808-16.

17 Hales BA, Morgan AW, Hart CA, Winstanley C. Variation in flagellin genes and proteins of Burkholderia cepacia. F Bacteriol 1998;180:1110-18.

18 Webb AK, Govan JRW. Burkholderia cepacia:another twist and a further threat. Thorax 1998;53:333-4.

19 Chace KV, Leahy DS, Martin R, Carabell R, Flux M, Sachdev GP. Respiratory mucous secretions in patients with cystic fibrosis: relationship between levels of highly sulfated mucin component and severity of the disease. Clin Chim Acta 1983;132:143-55.

20 Tsai HH, Hart CA, Rhodes JM. Production of mucin degrading sulphatase and glycosidases by Bacteroides thetaiotaomicron. Lett Appl Microbiol and glycosidases

21 Jansen HJ, Hart CA, Rhodes JM, Saunders JR, Smalley JW. A novel mucin sulfatase activity found in Burkholderia cepacia and Pseudomonas aeruginosa. $\mathcal{F}$ Med Microbiol. [In press.]

22 Winstanley C, Hales BA, Hart CA. Evidence for the presence in Burkholderia pseudomallei of a type III secretion system-associated gene cluster. $\mathcal{F}$ Med Microbiol. [In press.]

23 Haase A, Janzen J, Barrett S, Currie B. Toxin production by Burkholderia pseudomallei strains and correlation with severity of melioidosis. F Med Microbiol 1997;46:557-63.

24 Haußler S, Nimtz M, Domke T, Wray V, Steinmetz I. Purification and characterization of cytotoxic exolipid of Burkholderia pseudomallei. Infect Immun 1998;66:1588-93.

25 Sidhu H, Hoppe B, Hesse A, et al. Absence of Oxalobacter formigenes in cystic fibrosis patients: a risk factor for hyperoxaluria. Lancet 1998;352: cystic fib $1026-9$.

26 Felegie TP, Yu VL, Rumans LW, Yee RB. Susceptibility of Pseudomonas maltophilia to antimicrobial agents singly and in combination. Antimicrob

27 Vandamme P, Holmes B, Vancanneyt M, et al. Occurrence of multiple genomovars of Burkholderia cepacia in cystic fibrosis patients and proposal of Burkholderia multivorans sp. nov. Int f System Bacteriol 1997;47:1188200.

28 Bauernfeind A, Schneider I, Jungwirth R, Roller C. Discrimination of Burkholderia gladioli from other Burkholderia species in cystic fibrosis patients by PCR. F Clin Microbiol 1998;36:2748-51. 